\title{
南方海相不同类型烃源生烃模拟气态烃碳同位素 变化规律及成因判识指标
}

\author{
刘文汇 ${ }^{*}$ ，王杰，腾格尔，秦建中，郑伦举 \\ 中国石化石油勘探开发研究院无锡石油地质研究所, 无锡 214151 \\ * E-mail: whliu@pepris.com
}

收稿日期: 2011-04-18; 接受日期: 2011-09-25

石油化工联合基金项目(编号: 40739902)和国家重点基础研究发展计划项目(编号: 2005CB422102)资助

\begin{abstract}
摘要为了研究近似地质温度和压力双重作用下有机质成气演化过程及其产物的地球化学 特征, 利用常规高压釜热压模拟仪和仿真地层热压生烃模拟仪对比研究了南方海相干酪根、 固态和液态有机质成气过程及其地球化学特征, 发现不同类型原油(轻质油、凝析油)的模拟烃 气产率最高, 分散可溶有机质(固体沥青、重质油)烃气产率次之, 产率最低的为不同类型千酪 根, 在相同温度下烃气产率高低依次为: 轻质油(凝析油)>固体沥青>重质油>千酪根. 不同类 型干酪根与分散可溶有机质模拟气 $\mathrm{CO}_{2}$ 组分和同位素演化规律具有明显区别, 分散可溶有机 质模拟产物气的 $\delta^{13} \mathrm{C}_{\mathrm{CO}_{2}}-\delta^{13} \mathrm{C}_{1}$ 几乎都大于 $20 \%$, 而不同类型干酪根模拟产物气 $\delta^{13} \mathrm{C}_{\mathrm{CO}_{2}}-\delta^{13} \mathrm{C}_{1}$ 小于 $20 \%$ 。 不同类型烃源模拟气甲烷碳同位素组成具有随模拟温度增加不断变重的演化规律, 但无论何种类型气源, 在任何演化阶段产物气 $\delta^{13} \mathrm{C}_{1}$ 都不会重于其源碳同位素组成. 乙烷等碳 同位素组成也随温度增高逐渐变重, 演化至生烃高峰阶段时, 碳同位素组成接近其源的碳同 位素组成, 可以作为其母质类型的示踪指标. 当演化至高-过成熟阶段, 乙烷等重烃 $\delta^{13} \mathrm{C}$ 组成 会重于其烃源的碳同位素组成, 往往会显示出类似煤型气重烃气碳同位素组成偏重的特征, 故不能简单地用重烃碳同位素组成判断天然气母质类型. $\operatorname{Ln}\left(\mathrm{C}_{2} / \mathrm{C}_{3}\right)$ 是判断干酪根热解气与原 油(分散可溶有机质)裂解气的有效指标, 提出了 $\operatorname{Ln}\left(\mathrm{C}_{1} / \mathrm{C}_{2}\right)-\left(\delta^{13} \mathrm{C}_{1}-\delta^{13} \mathrm{C}_{2}\right)$ 为判断原油裂解气与 分散可溶有机质裂解气的有效指标.
\end{abstract}

前人对天然气的多种来源及其地球化学特征进 行了长期研究, 取得了重要进展和认识 ${ }^{[1 \sim 4]}$, 自然界 中很少存在同一来源从低成熟到高-过成熟阶段不同 阶段生成的完整天然气系列的产出, 对同一气源不 同演化阶段的天然气地球化学特征及其演化规律的 研究面临极大的困难. 前人在单一成气物质的生气
模拟及其地球化学特征研究作了大量的工作, 取得 了一系列的成果与认识 ${ }^{[5 \sim 9]}$, 论述了成气母质生气过 程和机理, 提出了不同的生烃动力学模型, 系统总结 了天然气地球化学特征演化规律, 开发出了原油裂 解气和干酪根热解气的判识指标和体系, 并应用到 生产实际中, 但仍有许多基本问题尚未得到彻底解

英文引用格式: Liu W H, Wang J, Tenger, et al. Stable carbon isotopes of gaseous alkanes as genetic indicators inferred from laboratory pyrolysis experiments of various marine hydrocarbon source materials from southern China. Sci China Earth Sci, 2012, 55: 966-974, doi: 10.1007/s11430-012-4392-5 
决, 一些判识指标应用范围有限, 特别对高演化阶段 的油型气，对单一来源不同演化阶段的天然气地球 化学特征还缺乏系统研究.

生烃模拟实验是系统开展天然气地球化学特征 演化、成气物质生烃转化过程及气源对比示踪研究的 重要手段, 理论基础是随着模拟温度升高, 有机大分 子经历与地质过程相似的逐步分解成小分子的过程. 根据动力学原理用温度来弥补时间对源岩生烃的地 质效应，最初的模拟实验基本上只考虑温度对生烃 过程的影响, 为了更全面考虑多种因素对生烃过程 的影响与接近实际地质情况, 此后进行的模拟实验 相继考虑有机质类型、温度、时间、压力、催化剂和 介质对产物特征的影响. 按照实验体系的封闭程度, 生烃模拟实验分为开放体系 ${ }^{[4]}$ 、半开放体系 ${ }^{[10]}$ 、封闭 体系 ${ }^{[11,12]}$, 不同的实验体系具有不同的优缺点, 通常 根据不同的研究目的和对象, 采用不同的生烃模拟 实验方法. 国内外大多数学者常用的判识干酪根热 解气和原油裂解气判识指标和图版就是采用封闭体 系黄金管模拟实验得到的 ${ }^{[5,13]}$. 本研究采用常规高压 釜封闭体系热压模拟和仿真地层半开放体系热压生 烃模拟对不同类型生气母质进行生气模拟试验, 系 统研究不同类型生气母质成气中高演化阶段天然气 地球化学基本特征及其演化规律.

\section{1 样品选择}

传统的生烃母质是按照不溶有机质干酪根的性 质划分的, 分为 I 型、 II 型和III型干酪根. 目前这种 母质类型划分已无法满足海相多元烃源生烃研究的 需要. 根据成烃母质性质、成因类型和演化程度等将
多元烃源划分为不溶、可溶以及酸溶有机质. 根据有 机质赋存形式又可划分为分散型、聚集型、化学型, 其中煤和油页岩为聚集型不溶有机质, 聚集型和分 散型不溶有机质是传统意义上的烃源岩; 源内、源外 分散可溶有机质和聚集型可溶有机质构成了再生烃

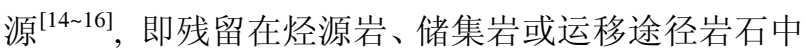
的固体沥青、稠油沥青、运移沥青或可溶有机质等分 散型可溶有机质可以再次生排烃 ${ }^{[17,18]}$. 分散和聚集 型可溶有机质经历后生演化或氧化改造, 形成改造 型可溶有机质, 是另一重要的再生烃源. 另外, 有机 质在成岩演化过程中, 伴随着有机-无机的相互作用, 形成有机-无机的复合体一一有机酸盐, 可能是一种 重要的化学烃源类型 ${ }^{[19]}$. 海相层系存在多种烃源(岩) 共存且相互转化、连续或叠置生烃特征, 尤其在南方 海相烃源岩普遍存在生气母质的物质状态转换和生 烃过程与贡献的接替, 呈现出“多源复合、多阶连续” 的天然气形成演化特点.

针对南方海相不同类型烃源共存的实际情况, 为 了系统研究不同类型烃源的模拟气态产物的地球化学 特征演化规律, 综合选取了不同类型烃源( I 型、II 型、III型干酪根, 凝析油, 轻质油, 重质油, 原生沥青, 沥青砂岩)9 件优质烃源岩和可溶有机质开展从 250 $550^{\circ} \mathrm{C}$ 共 7 个温度点的热压模拟实验, 样品基本地球 化学特征见表 1 .

\section{2 模拟实验及条件}

为了对比研究孔隙流体压力、生烃空间及高温高 压液态水对成烃有机质生烃过程以及气态产物地球 化学特征的影响, 生烃模拟实验分别在自行研制的

表 1 篮选进行模拟实验的不同类型烃源的地球化学基础数据 ${ }^{\text {a) }}$

\begin{tabular}{|c|c|c|c|c|c|c|c|c|c|}
\hline \multirow{2}{*}{ 样品位置 } & \multirow{2}{*}{ 样品编号 } & \multirow{2}{*}{ 样品类型 } & \multirow{2}{*}{ 层位 } & \multirow{2}{*}{$\begin{array}{c}\text { TOC } \\
(\%)\end{array}$} & \multirow{2}{*}{$\begin{array}{c}\text { 励青“A” } \\
\left(10^{-6}\right)\end{array}$} & \multicolumn{2}{|c|}{$\delta^{13} \mathrm{C}(\% \circ)$} & \multirow{2}{*}{$\begin{array}{c}\mathrm{HI} \\
(\mathrm{mg} / \mathrm{g})\end{array}$} & \multirow{2}{*}{$\begin{array}{r}R_{\mathrm{o}} / R_{\mathrm{b}} \\
(\%)\end{array}$} \\
\hline & & & & & & 干酪根 & 沥青“A” & & \\
\hline 普光东岳寨构造 & 川岳 84 井 & 凝析油 & $\mathrm{T}_{1} f$ & & & & -29.6 & & - \\
\hline 凯里虎庄构造 & 虎 47 井 & 轻质油 & $\mathrm{S}_{1} W n$ & & & & -31.7 & & - \\
\hline 西加拿大盆地 & CND & 重质油 & $\mathrm{D}$ & 10.59 & 147800 & & -30.0 & 673 & - \\
\hline 青川县火石村沥青矿 & GY-07-24 & 固体沥青 & $\epsilon$ & 78.67 & 229109 & & -35.8 & 510 & $0.5^{*}$ \\
\hline 青川县河家沟 & GY-07-28 & 沥青砂岩 & $\epsilon$ & 2.11 & 6531.3 & & -35.4 & 547 & - \\
\hline 广元长江沟 & GY-07-16 & 黑色泥岩/ II 型 & $\mathrm{P}_{2} d$ & 7.32 & 3027.1 & -26.0 & -27.1 & 365 & 0.7 \\
\hline 城口庙坝 & CK-06-02 & 黑色页岩/ I 型 & $\mathrm{S}_{1} l m$ & 6.02 & 960.4 & -29.8 & -28.7 & & $1.7^{*}$ \\
\hline 丹寨南甶 & NG-06 & 黑色页岩/ I 型 & $\epsilon_{1} j$ & 4.25 & 10.04 & & -29.1 & & $3.1^{*}$ \\
\hline 凯里渔洞大坡煤矿 & YD-4 & 煤/III型 & $\mathrm{P}_{2} l$ & 81.46 & 710.5 & -23.5 & -24.5 & 233 & 0.86 \\
\hline
\end{tabular}

a) 表中 $R_{\mathrm{o}} / R_{\mathrm{b}}$ 带*表示为沥青反射率 
常规高压釜封闭体系热压模拟仪和仿真地层半开放 体系热压生烃模拟仪上开展。常规高压釜热压模拟 实验在常压至 $25 \mathrm{MPa}$ 压力和室温至 $600^{\circ} \mathrm{C}$ 温度范围 内, 在特制的高压釜内加入一定量的样品, 按设定的 控温程序再现烃源在地质条件下的热演化过程. 而 仿真地层热压生烃模拟实验是在保留样品的原始孔 隙、有限的生烃空间里、与地质条件相近的地层流体 压力、上覆静岩压力条件下进行烃源岩的加温加压生 烃模拟实验.

为了尽可能接近地下实际地质条件, 实验条件 应结合研究区烃源的构造史、热史、埋藏史以及研究 目的与仪器特点进行选定. 本模拟实验条件如下: (1) 模拟温度: 为了研究烃源从低成熟 $\rightarrow$ 成熟 $\rightarrow$ 高成熟 $\rightarrow$ 过成熟整个演化阶段的气态烃演化规律, 选择 200 550 ${ }^{\circ} \mathrm{C}$ 不同温度点, 具体温度点设置与原始样品 起始成熟度有关. (2) 加温时间: 升温速率 $1^{\circ} \mathrm{C} / \mathrm{min}$, 恒温 48 96 h. (3) 加水量: 常规热压模拟加入样品重
量 $10 \%$ 50\%的水, 加热后为水蒸气状态; 仿真地层 模拟用水完全充满样品孔隙与反应釜空间, 水为高 压液态. (4) 体系流体压力: 常规热压模拟为常压 25 $\mathrm{MPa}$ 压力 (不可控), 仿真地层模拟为几个 150 $\mathrm{MPa}$ (可控), 具体大小依据烃源埋深设置. (5) 上覆静岩 压力: 常规热压模拟不能施加, 仿真地层模拟为几十 至 $200 \mathrm{MPa}$. (6) 样品状态: 常规热压模拟为粉碎样 品; 仿真地层模拟采用原始岩芯样品, 保留了样品的 原始孔隙与结构. 原油样中均加入了经过氯仿抽提 与高温密封处理的空白灰岩介质。

将样品和去离子水加入到反应釜中, 待反应釜 密封后抽成真空. 按照根据地层条件设计的温压条 件进行生烃模拟实验, 反应完毕, 待釜内温度降到 $150^{\circ} \mathrm{C}$ 时开始排烃(仿真地层模拟在升温恒温过程中, 如果流体压力超过设定值时需要排烃), 分别定量收 集生成的气态和液态产物. 对气态产物进行组分、碳 同位素分析, 结果见表 2.

表 2 不同类型烃源的模拟产物气地球化学特征 ${ }^{\text {a) }}$

\begin{tabular}{|c|c|c|c|c|c|c|c|c|c|}
\hline 样品号 & $\begin{array}{c}\text { 烃气 } \\
\left(\mathrm{m}^{3} / \mathrm{t} \mathrm{C}\right) \\
\end{array}$ & $\mathrm{CO}_{2}(\%)$ & $\mathrm{C}_{1}(\%)$ & $\mathrm{C}_{2}(\%)$ & $\mathrm{C}_{3}(\%)$ & $\delta^{13} \mathrm{C}_{\mathrm{CO}_{2}}(\% o)$ & $\delta^{13} \mathrm{C}_{1}(\% o)$ & $\delta^{13} \mathrm{C}_{2}(\% o)$ & $\delta^{13} \mathrm{C}_{3}(\% \circ)$ \\
\hline 虎 47 井-350 & 46.65 & $73.44^{*}$ & 10.07 & 5.08 & 2.90 & & -46.8 & -41.4 & -36.8 \\
\hline 虎 47 井-400 & 153.44 & $57.28^{*}$ & 13.67 & 9.04 & 5.93 & & -49.9 & -39.8 & -35.7 \\
\hline 虎 47 井-450 & 432.89 & $34.43^{*}$ & 26.25 & 14.04 & 8.43 & & -45.5 & -35.2 & -31.0 \\
\hline 虎 47 井-500 & 665.33 & $40.66^{*}$ & 35.68 & 12.25 & 1.29 & & -40.0 & -31.3 & -9.6 \\
\hline 虎 47 井-550 & 697.82 & $50.87^{*}$ & 30.17 & 5.91 & 0.01 & & -37.1 & -25.4 & \\
\hline 川岳 84 井-350 & 26.46 & $81.44^{*}$ & 4.55 & 3.95 & 2.95 & $-2.6^{*}$ & -48.2 & -40.2 & -34.0 \\
\hline 川岳 84 井-400 & 97.39 & $59.79^{*}$ & 12.71 & 10.03 & 6.01 & $-0.6^{*}$ & -49.3 & -37.8 & -32.6 \\
\hline 川岳 84 井-450 & 439.86 & $35.91^{*}$ & 24.66 & 14.56 & 9.20 & $-0.8^{*}$ & -43.0 & -33.4 & -28.6 \\
\hline 川岳 84 井-500 & 648.34 & $46.68^{*}$ & 29.82 & 11.80 & 2.31 & $-1.7^{*}$ & -37.7 & -29.4 & -17.9 \\
\hline 川岳 84 井-550 & 727.13 & $49.81^{*}$ & 29.25 & 5.59 & 0.01 & $-3.0^{*}$ & -34.5 & -21.6 & \\
\hline CND-250 & 0.16 & 61.87 & 2.95 & 0.35 & 0.29 & -11.2 & -42.7 & -34.1 & -32.9 \\
\hline CND-300 & 4.82 & 6.35 & 2.17 & 0.46 & 0.33 & -5.2 & -39.0 & -36.5 & -35.6 \\
\hline CND-350 & 43.87 & 32.23 & 20.46 & 8.35 & 5.78 & -2.8 & -43.7 & -37.4 & -35.4 \\
\hline CND-400 & 132.54 & 42.56 & 29.80 & 12.10 & 7.50 & -14.5 & -43.0 & -34.5 & -31.2 \\
\hline CND-450 & 291.36 & 21.58 & 48.06 & 14.26 & 4.92 & -12.1 & -39.4 & -31.4 & -20.9 \\
\hline CND-500 & 350.59 & 20.16 & 59.47 & 8.26 & 0.02 & -12.2 & -35.1 & -23.0 & \\
\hline CND-550 & 386.42 & 21.90 & 51.91 & 0.70 & 0.00 & -18.1 & -31.9 & -10.2 & \\
\hline GY-07-28-250 & 2.15 & 7.41 & 1.17 & 0.07 & 0.04 & -15.7 & -31.6 & -39.2 & -37.7 \\
\hline GY-07-28-300 & 7.08 & 53.74 & 13.57 & 2.45 & 1.45 & -13.9 & -44.6 & -40.9 & -39.4 \\
\hline GY-07-28-350 & 39.56 & 76.44 & 13.01 & 3.91 & 2.44 & -12.1 & -47.0 & -41.3 & -39.2 \\
\hline GY-07-28-400 & 55.66 & 89.11 & 7.08 & 1.92 & 1.02 & -9.2 & -46.3 & -39.2 & -36.2 \\
\hline GY-07-28-450 & 118.96 & 79.24 & 11.92 & 2.69 & 0.99 & -7.2 & -43.7 & -37.2 & -30.9 \\
\hline GY-07-28-500 & 223.88 & 61.29 & 24.20 & 3.85 & 0.02 & -8.9 & -40.7 & -31.4 & \\
\hline GY-07-28-550 & 289.24 & 51.81 & 27.37 & 0.99 & 0.00 & -11.4 & -38.7 & -19.6 & \\
\hline GY-07-24-250 & 0.31 & 0.29 & 0.86 & 0.22 & 0.07 & -15.4 & -45.3 & -38.1 & -34.3 \\
\hline GY-07-24-300 & 1.36 & 1.86 & 11.87 & 1.86 & 1.23 & -16.8 & -46.6 & -42.8 & -40.6 \\
\hline GY-07-24-350 & 36.36 & 2.76 & 27.21 & 10.77 & 7.34 & -22.9 & -49.8 & -41.9 & -40.2 \\
\hline
\end{tabular}


表 2(续)

\begin{tabular}{|c|c|c|c|c|c|c|c|c|c|}
\hline 样品号 & $\begin{array}{c}\begin{array}{c}\text { 烃气 } \\
\left(\mathrm{m}^{3} / \mathrm{t} \mathrm{C}\right)\end{array} \\
\end{array}$ & $\mathrm{CO}_{2}(\%)$ & $\mathrm{C}_{1}(\%)$ & $\mathrm{C}_{2}(\%)$ & $\mathrm{C}_{3}(\%)$ & $\delta^{13} \mathrm{C}_{\mathrm{CO}_{2}}(\% o)$ & $\delta^{13} \mathrm{C}_{1}(\% o)$ & $\delta^{13} \mathrm{C}_{2}(\% o)$ & $\delta^{13} \mathrm{C}_{3}(\%)$ \\
\hline GY-07-24-400 & 162.77 & 1.95 & 37.58 & 17.66 & 12.94 & -16.0 & -49.7 & -41.0 & -38.6 \\
\hline GY-07-24-450 & 299.70 & 2.88 & 54.38 & 18.13 & 9.41 & -20.0 & -46.0 & -36.9 & -30.4 \\
\hline GY-07-24-500 & 379.80 & 2.90 & 72.92 & 11.98 & 0.08 & -18.0 & -41.9 & -26.7 & \\
\hline GY-07-24-550 & 456.35 & 6.45 & 63.19 & 3.43 & 0.00 & -28.2 & -39.5 & -19.1 & \\
\hline DK-GY-07-24-300 & 0.29 & $17.6^{*}$ & 0.44 & 0.06 & 0.02 & $-3.6^{*}$ & -44.8 & -38.0 & -34.0 \\
\hline DK-GY-07-24-350 & 1.94 & $43.8^{*}$ & 1.22 & 0.40 & 0.27 & $0.4^{*}$ & -49.9 & -40.1 & -38.1 \\
\hline DK-GY-07-24-400 & 35.98 & $58.2^{*}$ & 17.61 & 6.79 & 4.20 & $-0.3^{*}$ & -50.6 & -40.8 & -39.2 \\
\hline DK-GY-07-24-450 & 176.07 & $37.2^{*}$ & 30.88 & 13.63 & 9.25 & $-0.5^{*}$ & -48.4 & -40.6 & -37.6 \\
\hline DK-GY-07-24-500 & 315.77 & $24.8^{*}$ & 53.40 & 15.07 & 4.62 & $-2.7^{*}$ & -44.5 & -34.5 & -23.9 \\
\hline DK-GY-07-24-550 & 406.35 & $27.8^{*}$ & 58.10 & 10.42 & 0.99 & $-1.1^{*}$ & -42.0 & -28.5 & -23.6 \\
\hline GY-07-16-250 & 0.18 & 30.43 & 2.30 & 0.26 & 0.16 & & -48.7 & -37.4 & -35.1 \\
\hline GY-07-16-300 & 2.13 & 67.48 & 10.60 & 3.88 & 1.87 & & -41.1 & -35.6 & -32.9 \\
\hline GY-07-16-350 & 26.38 & 32.75 & 23.77 & 10.59 & 5.17 & & -40.9 & -32.7 & -31.0 \\
\hline GY-07-16-400 & 104.23 & 34.67 & 30.13 & 10.50 & 5.24 & & -38.4 & -30.3 & -28.6 \\
\hline GY-07-16-450 & 168.30 & 43.24 & 37.19 & 9.24 & 3.45 & & -34.9 & -27.3 & -20.5 \\
\hline GY-07-16-500 & 269.12 & 46.95 & 40.68 & 4.84 & 0.03 & & -31.9 & -17.9 & \\
\hline GY-07-16-550 & 350.68 & 49.96 & 36.82 & 0.98 & 0.01 & & -30.0 & -11.8 & \\
\hline CK-06-02-350 & 12.20 & 33.57 & 30.01 & 9.82 & 5.67 & -28.1 & -41.9 & -35.2 & -32.7 \\
\hline CK-06-02-400 & 46.77 & 3.64 & 20.41 & 5.20 & 2.92 & -22.5 & -38.5 & -33.1 & -30.2 \\
\hline CK-06-02-450 & 163.02 & 3.14 & 33.66 & 5.84 & 0.84 & -20.9 & -32.1 & -29.5 & -16.9 \\
\hline CK-06-02-500 & 202.41 & 5.07 & 40.42 & 6.27 & 0.15 & -23.5 & -32.4 & -27.0 & -8.4 \\
\hline CK-06-02-550 & 228.84 & 6.02 & 49.54 & 3.12 & 0.01 & -22.7 & -32.9 & -19.3 & \\
\hline YD-4-300 & 1.48 & 21.5 & 36.29 & 8.67 & 3.23 & -16.1 & -34.8 & -29.0 & -27.0 \\
\hline YD-4-350 & 16.17 & 23.8 & 42.71 & 14.85 & 6.95 & -19.5 & -36.0 & -26.9 & -25.7 \\
\hline YD-4-400 & 62.15 & 11.7 & 54.49 & 13.01 & 5.56 & -17.9 & -33.0 & -25.2 & -24.1 \\
\hline YD-4-450 & 114.69 & 9.8 & 69.35 & 9.72 & 1.88 & -17.0 & -29.1 & -21.5 & -14.2 \\
\hline YD-4-500 & 133.12 & 10.7 & 67.49 & 4.03 & 0.03 & -18.3 & -27.4 & -12.8 & \\
\hline YD-4-550 & 144.39 & 14.9 & 67.77 & 0.84 & 0.00 & -20.9 & -25.7 & -11.4 & \\
\hline DK-YD-4-300 & 0.02 & 3.3 & 1.14 & 0.16 & 0.08 & -14.5 & -41.3 & -33.0 & -27.7 \\
\hline DK-YD-4-350 & 0.24 & 5.0 & 15.16 & 2.48 & 0.78 & -14.3 & -38.4 & -30.6 & -27.5 \\
\hline DK-YD-4-400 & 26.53 & 15.1 & 58.09 & 16.34 & 5.96 & -16.2 & -36.8 & -25.7 & -23.7 \\
\hline DK-YD-4-450 & 75.18 & 13.6 & 68.12 & 12.74 & 4.01 & -18.2 & -32.4 & -22.8 & -21.2 \\
\hline DK-YD-4-500 & 125.32 & 9.8 & 82.52 & 5.84 & 0.92 & -17.7 & -27.3 & -17.2 & -15.0 \\
\hline DK-YD-4-550 & 138.47 & 14.9 & 81.75 & 1.86 & 0.07 & -20.2 & -24.9 & -13.4 & \\
\hline NG-06-350 & 2.85 & 24.6 & 12.78 & 0.26 & 0.06 & -21.8 & -35.0 & -40.4 & -37.3 \\
\hline NG-06-400 & 2.58 & 20.1 & 4.54 & 0.12 & 0.02 & -23.1 & -39.8 & -32.5 & -27.6 \\
\hline NG-06-450 & 5.00 & 23.7 & 5.39 & 0.11 & 0.01 & -26.8 & -31.9 & -31.2 & -25.4 \\
\hline NG-06-500 & 10.83 & 10.0 & 5.48 & 0.39 & 0.01 & -24.0 & -32.6 & -30.0 & -18.9 \\
\hline NG-06-550 & 12.87 & 24.6 & 10.98 & 0.13 & 0.00 & -15.7 & -31.1 & -22.0 & \\
\hline
\end{tabular}

a) 样品号中最后的数字代表模拟温度; 样品号前的“DK”代表仿真地层热压模拟，无“DK”代表常规高压釜热压模拟; 数字后带*表明 该样品模拟时加入了人工灰岩, $\mathrm{CO}_{2}$ 数据仅供参考

\section{3 结果与讨论}

\section{1 气态产物组成及其演化特征}

模拟产物气主要有烃气、 $\mathrm{CO}_{2}$ 和 $\mathrm{H}_{2}$, 还包括少量 $\mathrm{N}_{2}$ 和 CO. 从表 2 和图 1 可以发现，总体上原油模拟 烃气产率最高, 尤其在 $400^{\circ} \mathrm{C}$ 以后烃气产率快速增加, 到 $500^{\circ} \mathrm{C}$ 以后烃气产率增长趋势变缓. 分散可溶有机
质烃气产率次之, 产率最低的为不同类型干酪根. 不 同类型烃源模拟产物烃气产率与烃源本身的可溶有 机质含量高低有密切关系, 烃源可溶有机质含量越高, 相同温度下模拟产物烃气产率越高. 烃源岩模拟产物 烃气产率与其有机碳含量具有较好的正相关性，与烃 源岩成熟度具有较好负相关性. 在有机碳含量、可溶 有机质含量以及成熟度相当的条件下，烃源有机质 


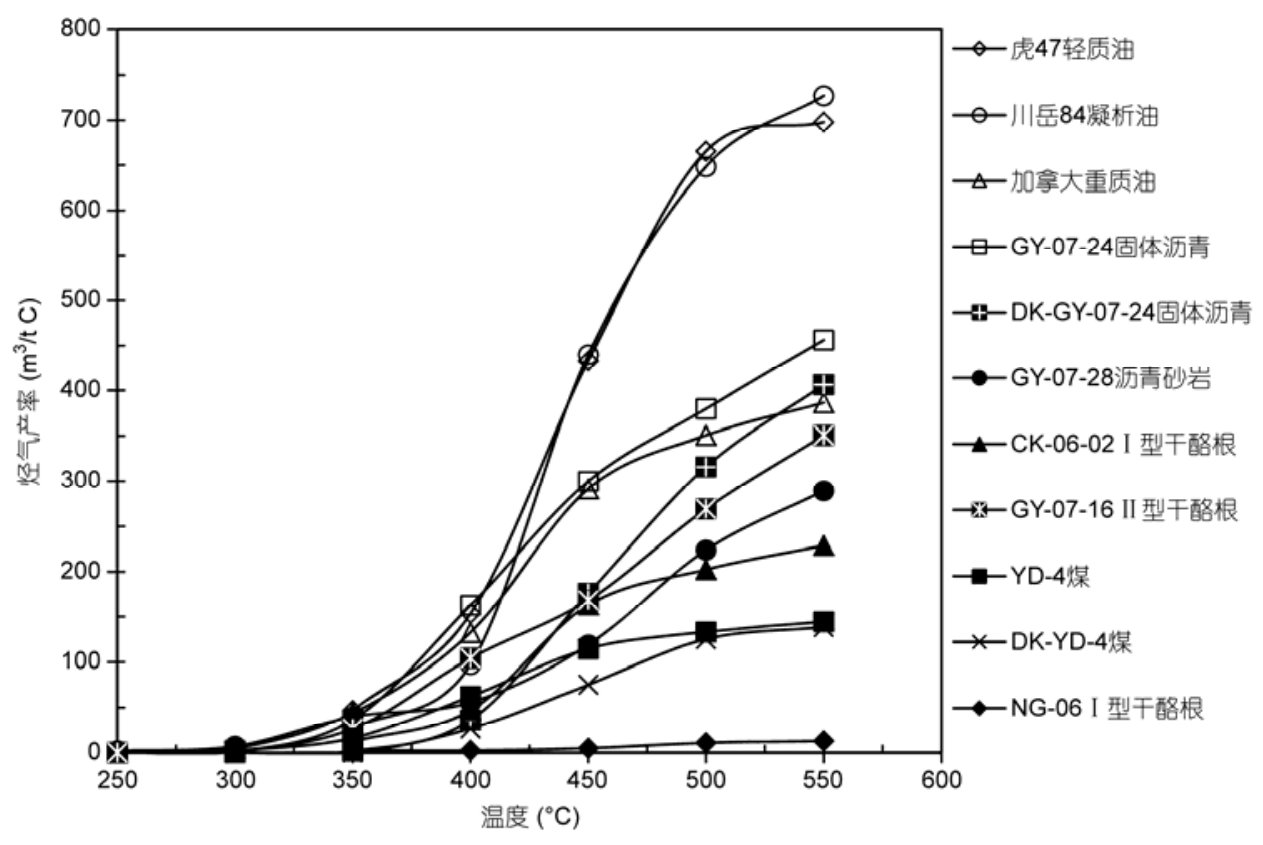

图 1 不同形式烃源生烃模拟产物烃类气产率的变化特征

类型越好, 产率相对越高. 对于两种不同模拟方式, 在相同温度条件下, 仿真地层热压模拟烃气产率要 低于常规热压模拟, 但随着模拟温度的增加, 二者之 间的差异逐渐变小.

模拟产物烃气组成以甲烷为主, 随模拟温度增 加甲烷相对含量逐渐增加, 但到 $500^{\circ} \mathrm{C}$ 之后, 甲烷相 对含量逐渐降低. 重烃气相对含量也随着模拟温度 增加而逐渐增加, 但到了 $400^{\circ} \mathrm{C}$ 或 $500^{\circ} \mathrm{C}$ 之后, 重烃 气相对含量逐渐降低, 重烃气相对含量变化的拐点 温度与烃源类型有关, 有机质类型越好, 拐点温度越 滞后. 甲烷相对含量降低的拐点温度要高于乙烷等重 烃, 表现出一定的迟滞效应, 可能与重烃在 450 $500^{\circ} \mathrm{C}$ 出现快速热裂解成甲烷有关.

由图 2 可见, 不同类型干酪根与分散可溶有机质 $\mathrm{CO}_{2}$ 模拟气组分和同位素演化规律具有明显区别. 分散 可溶有机质模拟产物气的 $\delta^{13} \mathrm{C}_{\mathrm{CO}_{2}}-\delta^{13} \mathrm{C}_{1}$ 几乎都大于 $20 \%$ ，而不同类型干酪根模拟产物气 $\delta^{13} \mathrm{C}_{\mathrm{CO}_{2}}-\delta^{13} \mathrm{C}_{1}$ 小 于 $20 \%$, 二者具有明显的差异, 说明了在热裂解成 气过程中, 随着二氧化碳和甲烷的大量生成, 分散可 溶有机质生成的 $\mathrm{CO}_{2}$ 和 $\mathrm{CH}_{4}$ 之间同位素分馏程度要 比不同类型干酪根的大. 除广元沥青砂岩和加拿大 重质油砂外, 随模拟产物气中 $\mathrm{CO}_{2}$ 含量增加, $\mathrm{CO}_{2}$ 碳 同位素组成总体上有变轻的趋势. 广元沥青和加拿
大重质油随着模拟产物气中 $\mathrm{CO}_{2}$ 含量增加, $\mathrm{CO}_{2}$ 碳同 位素组成总体上逐渐变重, 可能与其高含量的碳酸 盐岩热裂解有关.

\section{2 烃类气体碳同位素组成演化}

原油和分散可溶有机质产物甲烷气碳同位素组 成均呈现出先变轻再变重的演化特征. 在裂解早期, 甲烷碳同位素组成出现先变轻后变重的“倒转”现象, 低温阶段烃类的裂解和聚合作用可能是造成这种现 象的原因 ${ }^{[20]}$. 产物甲烷气碳同位素组成随着热演化 程度的增加逐渐变重, 且呈现单一曲线变化, 但不会 重于其源的干酪根或沥青“A”碳同位素组成. 总体上 碳同位素组成较轻的烃源其产物气碳同位素演化曲 线总体上要轻于碳同位素组成较重的烃源产物气碳 同位素组成(见图 3). 模拟产物气甲烷碳同位素组成 越轻，其母质碳同位素组成也越轻，但由于甲烷碳同 位素受热演化程度的影响较大, 所以只有在热演化 程度相当的情况下, 甲烷气碳同位素组成可以在一 定程度上示踪其来源.

由图 3 可见, 随着热演化程度的增加, 乙烷和丙 烷碳同位素组成逐渐变重，当达到高成熟期(450 $500^{\circ} \mathrm{C}$ ) 时, 即烃源处在生烃气高峰时(见图 1), 重烃气 碳同位素组成接近母质碳同位素组成, 可以代表 


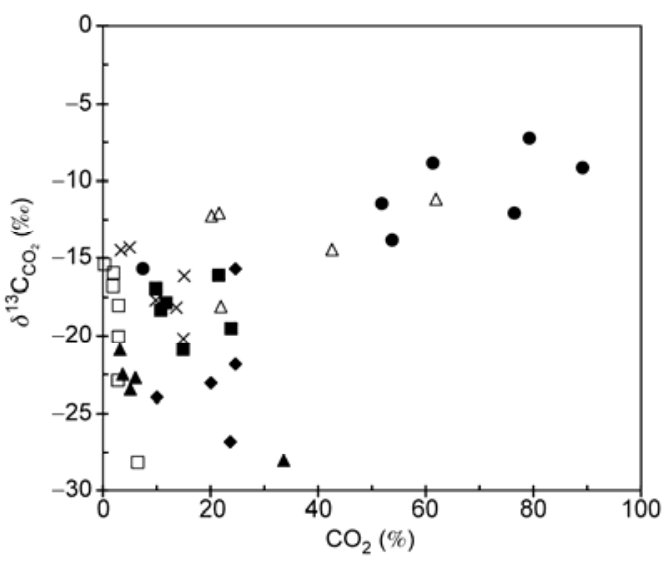

$\Delta$ 加拿大重质油。GY-07-24固体沥青 - YD-4煤 $\quad \times$ DK-YD-4煤

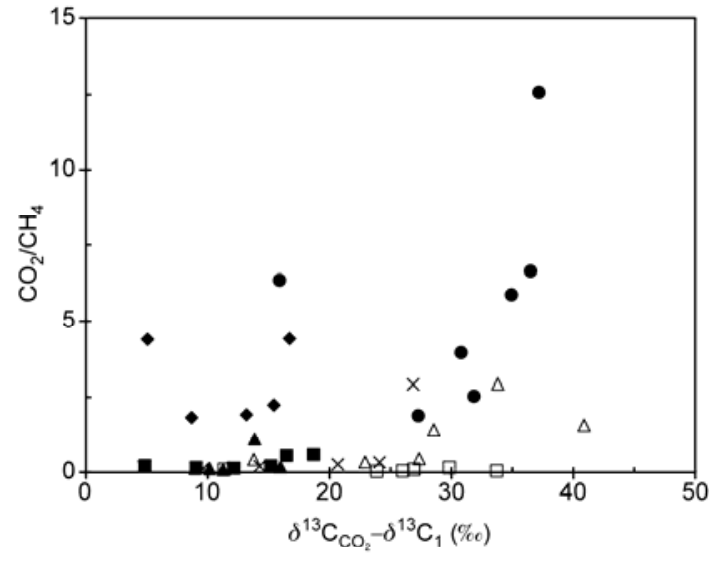

• GY-07-28沥青眇岩、^CK-06-02 I 型干酪根 -NG-06 I 型干酪根

图 2 不同形式烃源模拟气中 $\mathrm{CO}_{2}$ 含量与 $\delta^{13} \mathrm{C}_{\mathrm{CO}_{2}}$ 以及 $\delta^{13} \mathrm{C}_{\mathrm{CO}_{2}}-\delta^{13} \mathrm{C}_{1}$ 与 $\mathrm{CO}_{2} / \mathrm{CH}_{4}$ 关系
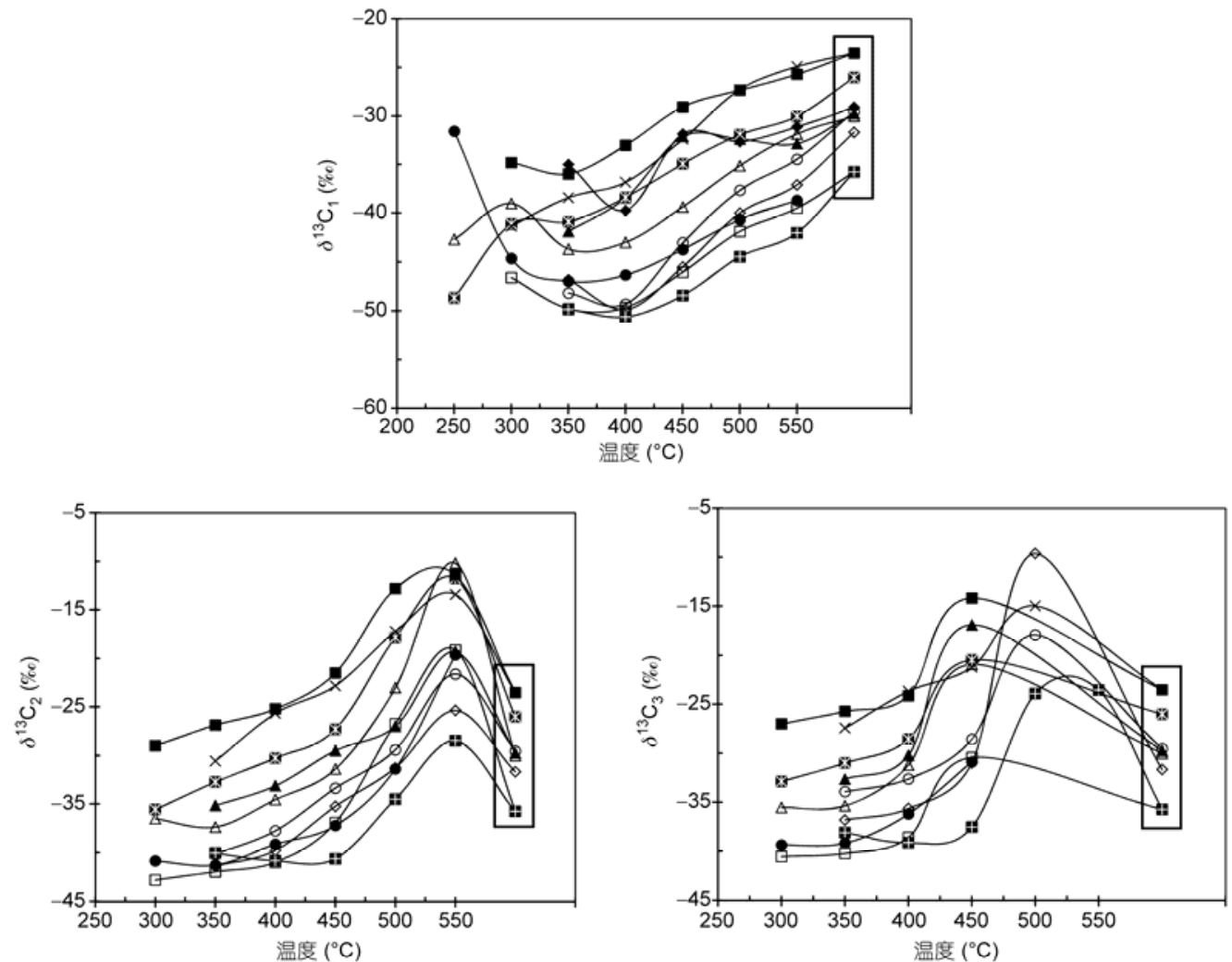

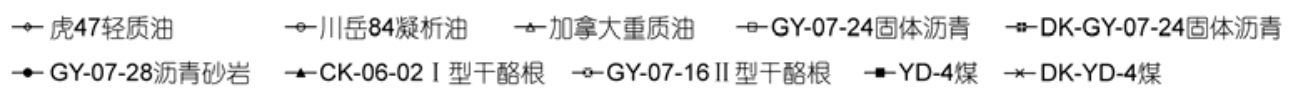

图 3 不同类型烃源模拟产物烷烃气碳同位素组成演化规律 方框代表烃源碳同位素值 
母质碳同位素组成, 具有烃源示踪意义, 可以作为气 源对比指标. 另外, 不同类型干酪根模拟产物重烃气 碳同位素组成接近其母质碳同位素组成所对应的模 拟温度 $\left(450^{\circ} \mathrm{C}\right)$ 要小于分散可溶有机质模拟产物重烃 气碳同位素组成接近其母质碳同位素组成所对应的 模拟温度 $\left(500^{\circ} \mathrm{C}\right)$. 说明干酪根大量降解生成烃气的 所需要的活化能比原油和分散可溶有机质大量裂解 成烃气所需要的活化能低, 同位素逐渐演化至接近 母质碳同位素组成要比原油和分散可溶有机质要快, 但生气量远小于原油和分散可溶有机质裂解气. 造 成原油裂解气甲烷碳同位素偏轻的原因是从干酪根 到油的转化过程中已发生了一定程度的碳同位素分 馏. 同时, 由于大部分甲烷来自 $\mathrm{C}_{2}$ 等重烃的裂解, 并 且在裂解阶段 $\mathrm{C}_{2}$ 等重烃的碳同位素值都要小于原油 全油碳同位素值, 因此其生成的甲烷碳同位素值必 然偏轻. 在相同温度条件下, 仿真地层热压模拟甲 烷、乙烷碳同位素组成比常规热压模拟甲烷和乙烷碳 同位素组成轻, 可能与压力造成同位素分馏效应差 异有关.

无论是不同类型干酪根还是原油、分散可溶有机 质, 均随着热演化程度增加, 产物气甲烷和乙烷碳同 位素组成逐渐变重, 且二者呈较好的线性关系(见图 4). 当达到较高热演化程度时, 原油、分散可溶有机
质以及 I 型、II 型干酪根产物气乙烷碳同位素值都大 于目前大多数学者所用煤型气和油型气的界限值 $(-28 \% \circ \text { 或 }-29 \% \circ)^{[21,22]}$. 另外, 在高过成熟阶段 $(>400 \sim$ $500^{\circ} \mathrm{C}$, 即 $R_{0}>1.5$ ), 不同烃源模拟气乙烷、丙烷 $\delta^{13} \mathrm{C}$ 值大于其烃源的碳同位素值(见图 3 和 4), 所以不能 简单地用重烃碳同位素组成判断天然气母质类型, 应该结合其他指标综合判断.

\section{3 干酪根热解气与不同状态可溶有机质裂解气 地球化学特征和判识}

通过对不同类型烃源热模拟产物气的组成分析, 发现不同类型干酪根与分散可溶有机质模拟产物气 $\operatorname{Ln}\left(\mathrm{C}_{1} / \mathrm{C}_{2}\right)$ 变化范围没有明显差异, 且变化趋势也相 同. 但原油裂解气 $\operatorname{Ln}\left(\mathrm{C}_{1} / \mathrm{C}_{2}\right)$ 变化范围比分散可溶有机 质要小 (见图 5), 这与原油裂解气主要是长链脂肪结构 碳的断裂, 而分散可溶有机质饱和烃含量相对较低, 重质组分含量相对较高有关. 原始母质的有机组成复 杂程度决定着所产气体组分的分布特征, 原始有机质 组成越单一, 生成的气态烃组分特征越一致.

不同类型干酪根与原油、分散可溶有机质在 $\operatorname{Ln}\left(C_{2} / C_{3}\right)$ 变化规律上具有明显差异(见图 6), 在热模 拟温度较低时, 原油和分散可溶有机质热模拟产物 气 $\operatorname{Ln}\left(\mathrm{C}_{2} / \mathrm{C}_{3}\right)$ 变化很小, 但当模拟温度达到 $450 \sim 550^{\circ} \mathrm{C}$

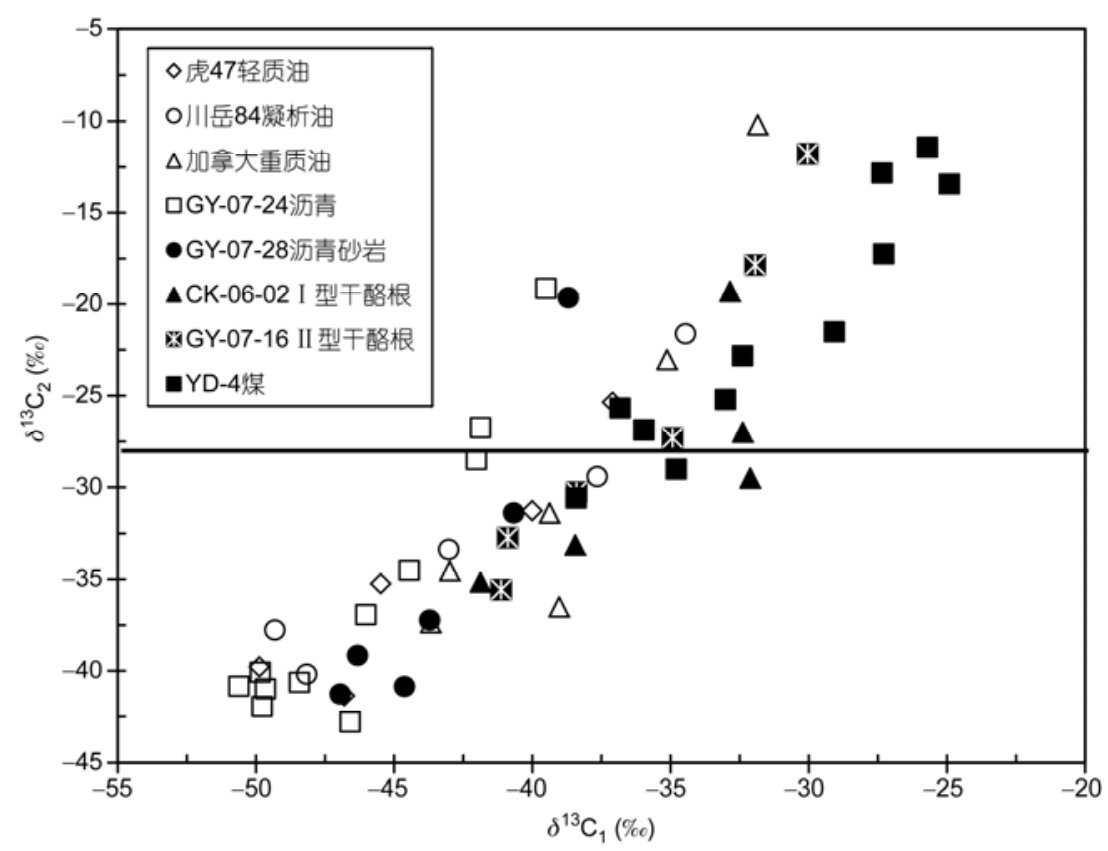

图 4 不同形式烃源热模拟产物气甲烷与乙烷碳同位素组成变化规律 

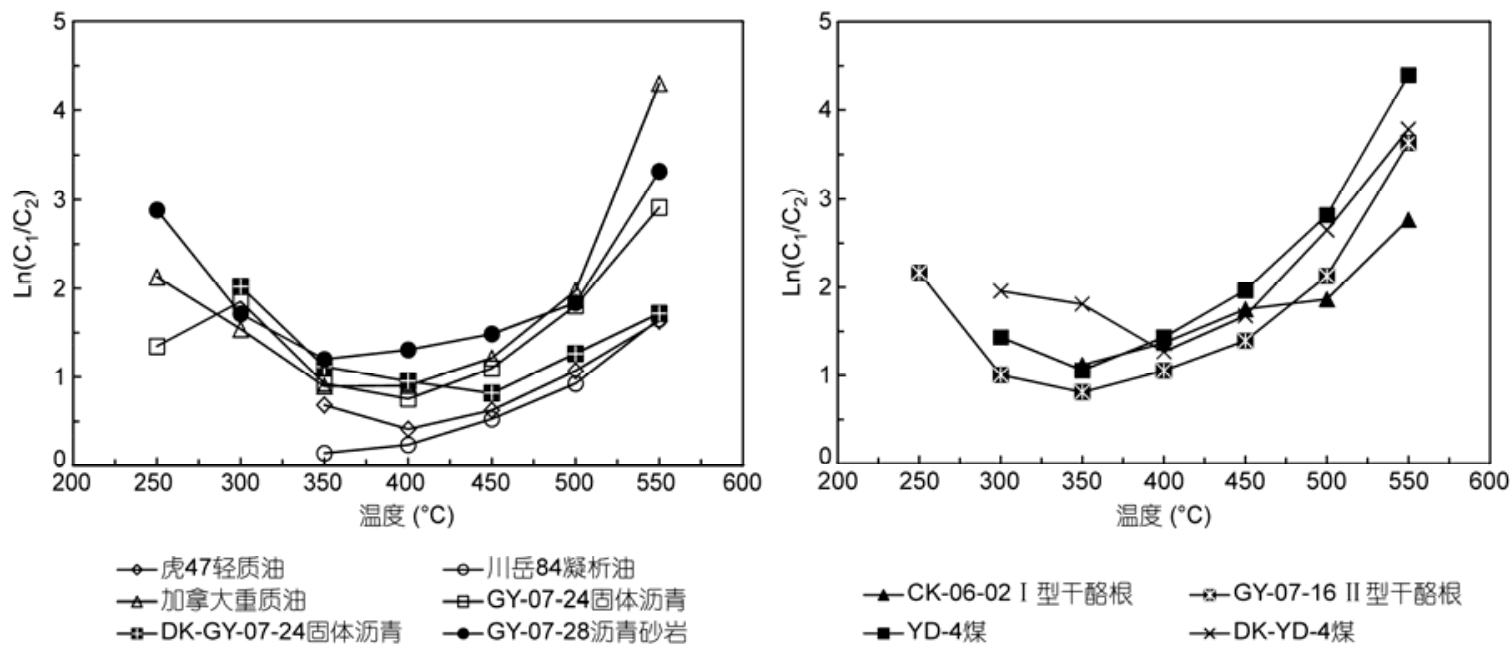

图 5 不同形式烃源热模拟产物气 $\operatorname{Ln}\left(C_{1} / C_{2}\right)$ 随热模拟温度变化规律
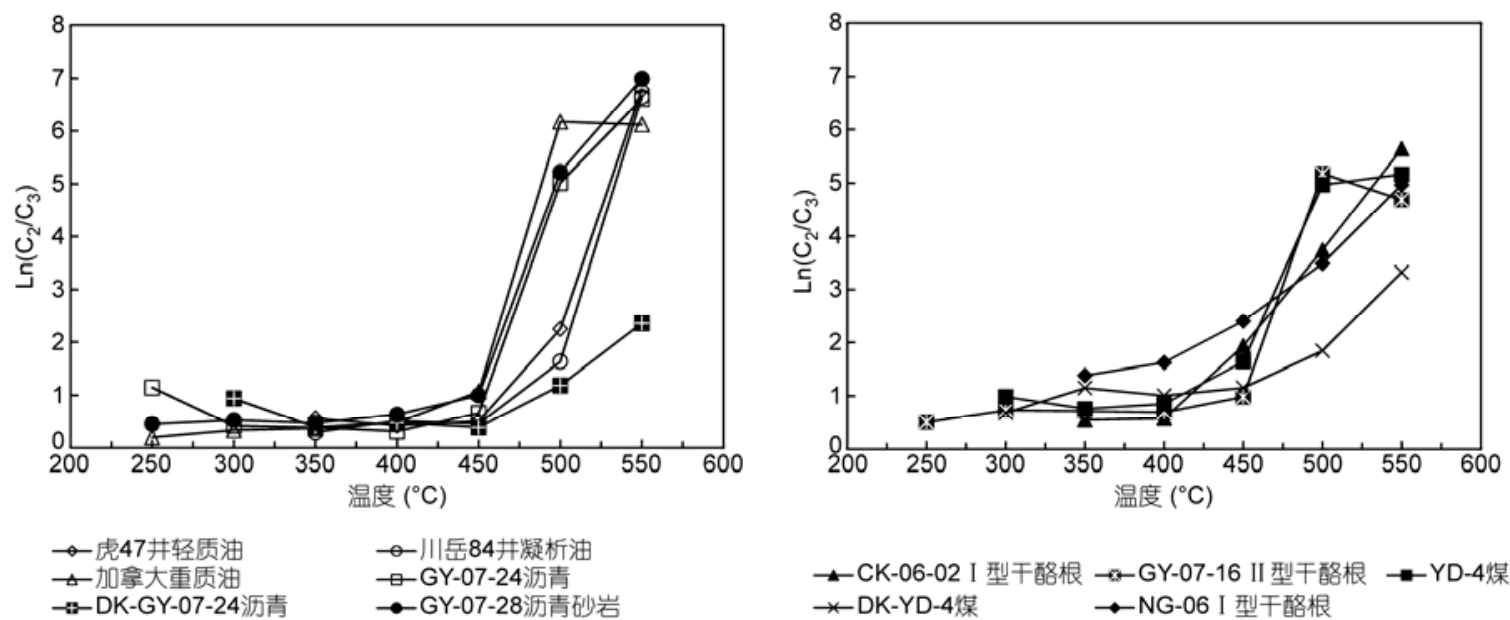

图 6 不同形式烃源热模拟产物气 $\operatorname{Ln}\left(\mathrm{C}_{2} / \mathrm{C}_{3}\right)$ 随热模拟变化规律

时, $\operatorname{Ln}\left(\mathrm{C}_{2} / \mathrm{C}_{3}\right)$ 快速增大, $\mathrm{C}_{2}$ 组分稳定增加, $\mathrm{C}_{3}$ 组分快 速降低，正好与烃气生成高峰吻合(见图 1). 而不同 类型干酪根产物气 $\operatorname{Ln}\left(\mathrm{C}_{2} / \mathrm{C}_{3}\right)$ 随热模拟温度的增加而 规律性增加.

前人研究发现 ${ }^{[5,13,23]}$, 原油裂解气 $\mathrm{C}_{1} / \mathrm{C}_{2}$ 比值变 化较小, 而 $\mathrm{C}_{2} / \mathrm{C}_{3}$ 比值变化范围较大, 由于 $\mathrm{C}_{3}$ 裂解成 $\mathrm{C}_{1}$ 和 $\mathrm{C}_{2}, \mathrm{C}_{3}$ 裂解速率较大, 致使 $\mathrm{C}_{3}$ 相对含量的变化 范围较大. 干酪根热解气 $\mathrm{C}_{1} / \mathrm{C}_{2}$ 比值变化较大, $\mathrm{C}_{2} / \mathrm{C}_{3}$ 比值变化较小, $\mathrm{C}_{1}$ 增长较快, $\mathrm{C}_{2}$ 和 $\mathrm{C}_{3}$ 保持着相对稳定 的量, 所生成的 $\mathrm{C}_{1}$ 量变化范围较大. 本研究发现在 生烃高峰阶段之前, 不论是干酪根热解气, 还是原油 (分散可溶有机质)裂解气, $\operatorname{Ln}\left(\mathrm{C}_{2} / \mathrm{C}_{3}\right)$ 变化范围都较小, $\operatorname{Ln}\left(\mathrm{C}_{1} / \mathrm{C}_{2}\right)$ 变化范围都较大, 总体上原油(分散可溶有
机质)裂解气 $\operatorname{Ln}\left(\mathrm{C}_{1} / \mathrm{C}_{2}\right)$ 变化范围比干酪根热解气大, 原油裂解气 $\operatorname{Ln}\left(\mathrm{C}_{1} / \mathrm{C}_{2}\right)$ 主要分布在 $0 \sim 2$ 内, 但其值相 对较小, 而干酪根热解气 $\operatorname{Ln}\left(\mathrm{C}_{1} / \mathrm{C}_{2}\right)$ 主要分布在 1 2 内, 但其值相对较大; 当达到生烃高峰至过成熟阶段, 不同类型干酪根与原油(分散可溶有机质)在 $\mathrm{Ln}\left(\mathrm{C}_{2} / \mathrm{C}_{3}\right)$ 变化规律上具有明显差异, 相对于 $\operatorname{Ln}\left(\mathrm{C}_{1} / \mathrm{C}_{2}\right)$, 原油 (分散可溶有机质)裂解气 $\mathrm{Ln}\left(\mathrm{C}_{2} / \mathrm{C}_{3}\right)$ 变化范围明显比 干酪根热解气要大, 而且随着热模拟温度的增加, 原 油(分散可溶有机质)裂解产生的天然气 $\operatorname{Ln}\left(\mathrm{C}_{2} / \mathrm{C}_{3}\right)$ 增 加速率明显比干酪根热解产生的天然气要大, 表现 出在 $\operatorname{Ln}\left(\mathrm{C}_{1} / \mathrm{C}_{2}\right)-\operatorname{Ln}\left(\mathrm{C}_{2} / \mathrm{C}_{3}\right)$ 图上, 原油裂解气的斜率大 于干酪根热解气(见图 7), 与前人认识不一致, 修正 了前人经典图版的不足之处 ${ }^{[13]}, \operatorname{Ln}\left(\mathrm{C}_{2} / \mathrm{C}_{3}\right)$ 是判断干 

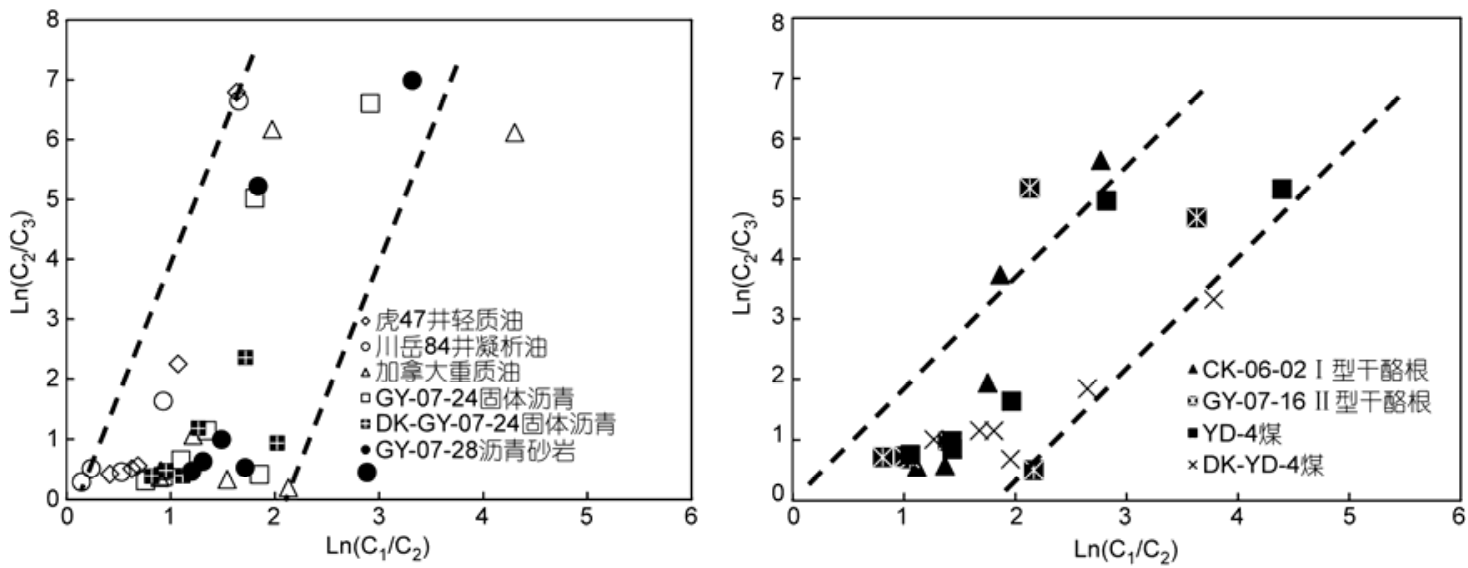

图 7 不同形式烃源热模拟产物气 $\operatorname{Ln}\left(C_{1} / C_{2}\right)$ 与 $\operatorname{Ln}\left(C_{2} / C_{3}\right)$ 变化规律

酪根热解气与原油(分散可溶有机质)裂解气的有效 指标(尤其在生烃高峰阶段至过成熟阶段).

前人 ${ }^{[5,13,23 ~ 25]}$ 常把 $\operatorname{Ln}\left(\mathrm{C}_{2} / \mathrm{C}_{3}\right)-\left(\delta^{13} \mathrm{C}_{2}-\delta^{13} \mathrm{C}_{3}\right)$ 的关 系作为判别干酪根热解气与原油裂解气的重要指标, 并应用到美国安哥拉和堪萨斯、中国塔里木盆地等天 然气来源判识. 研究发现 $\operatorname{Ln}\left(\mathrm{C}_{2} / \mathrm{C}_{3}\right)-\left(\delta^{13} \mathrm{C}_{2}-\delta^{13} \mathrm{C}_{3}\right)$ 的 相关关系并不能用来对天然气来源进行判识, 我们研 究发现原油与分散可溶有机质在 $\operatorname{Ln}\left(\mathrm{C}_{1} / \mathrm{C}_{2}\right)-\left(\delta{ }^{13} \mathrm{C}_{1}-\right.$ $\delta^{13} \mathrm{C}_{2}$ ) 关系图上有明显差异(见图 8), 分散可溶有机 质裂解气 $\operatorname{Ln}\left(\mathrm{C}_{1} / \mathrm{C}_{2}\right)$ 变化范围较大, $\left(\delta^{13} \mathrm{C}_{1}-\delta^{13} \mathrm{C}_{2}\right)$ 差 异也较大, 而原油裂解气 $\operatorname{Ln}\left(\mathrm{C}_{1} / \mathrm{C}_{2}\right)$ 和 $\left(\delta^{13} \mathrm{C}_{1}-\delta^{13} \mathrm{C}_{2}\right)$

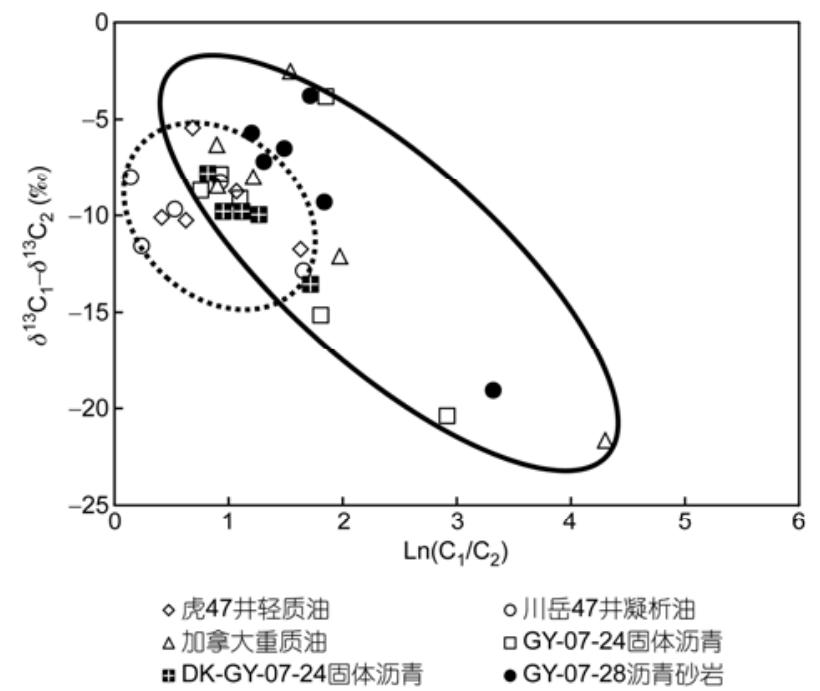

图 8 不同形式烃源热模拟产物气 $\operatorname{Ln}\left(\mathrm{C}_{1} / \mathrm{C}_{2}\right)$ 与 $\delta^{13} \mathrm{C}_{1}-\delta^{13} \mathrm{C}_{2}$ 变化特征
变化范围均较小, 本研究中原油以长链脂肪族化合 物为主, 有机组成相对单一, 裂解气的 $\mathrm{C}_{1} / \mathrm{C}_{2}$ 比值和 $\delta^{13} \mathrm{C}_{1}-\delta{ }^{13} \mathrm{C}_{2}$ 变化范围相对较小, 而分散可溶有机质 的有机组成相对复杂, 裂解气的 $\mathrm{C}_{1} / \mathrm{C}_{2}$ 比值和 $\delta^{13} \mathrm{C}_{1}-$ $\delta^{13} \mathrm{C}_{2}$ 变化范围相对较大, 所以原始母质的有机组成 复杂程度决定着所产气体组分和同位素的分布特征, 我们认为 $\operatorname{Ln}\left(\mathrm{C}_{1} / \mathrm{C}_{2}\right)-\left(\delta^{13} \mathrm{C}_{1}-\delta{ }^{13} \mathrm{C}_{2}\right)$ 可以作为判断原油 裂解气与分散可溶有机质裂解气的有效指标.

\section{4 结论}

对不同类型烃源进行常规高压釜封闭体系热压 模拟和仿真地层半开放体系热压生烃模拟实验研究 发现，无论是封闭体系，还是半开放体系，二者在烃 气产率、组分和同位素组成特征都具有相同的变化规 律，主要取得了以下几个重要认识:

(1) 随热模拟温度增加, 不同类型烃源生成的气 体甲烷和重烃相对含量逐渐增加, 但当达到一定温 度后, 甲烷和重烃相对含量开始下降, 甲烷相对含量 降低的趋势要晚于重烃气, 烃气产率和组分变化特 征与其直接母质类型密切相关.

(2) 烃类气体碳同位素组成具有随热模拟温度 增高逐渐变重的演化规律, 甲烷碳同位素组成不会 重于其源的碳同位素组成. 当演化到生烃高峰阶段 时，乙烷、丙烷碳同位素组成接近其源碳同位素组成， 具有烃源示踪意义. 但当演化至高-过成熟阶段, 乙 烷等 $\delta{ }^{13} \mathrm{C}$ 值大于其烃源的碳同位素值, 故不能简单 地用重烃气碳同位素组成判断母质类型. 
(3) 烃气组分和同位素变化特征主要受天然气 母质类型控制. 烃源的碳同位素组成决定产物烃气 碳同位素组成的演化规律, 碳同位素组成较轻的烃 源其产物烃气碳同位素组成演化曲线总体上要轻于 碳同位素组成较重的烃源产物烃气碳同位素组成, 明显表现出了气体碳同位素组成的继承效应.
(4) $\mathrm{Ln}\left(\mathrm{C}_{2} / \mathrm{C}_{3}\right)$ 是判识不同类型干酪根热解气与原 油(分散可溶有机质)裂解气的有效指标，修正了 Prinzhofer 的判识指标和图版. 原油与分散可溶有机 质在 $\operatorname{Ln}\left(\mathrm{C}_{1} / \mathrm{C}_{2}\right)-\left(\delta^{13} \mathrm{C}_{1}-\delta^{13} \mathrm{C}_{2}\right)$ 关系图上也具有明显差 异, $\operatorname{Ln}\left(\mathrm{C}_{1} / \mathrm{C}_{2}\right)-\left(\delta^{13} \mathrm{C}_{1}-\delta^{13} \mathrm{C}_{2}\right)$ 可以作为判断原油裂解 气与分散可溶有机质裂解气的有效指标.

致谢感谢审稿专家提出的宝贵意见.

\section{参考文献}

1 马永生. 普光气田天然气地球化学特征及气源探讨. 天然气地球科学, 2008, 19: 1-9

2 刘文汇，张殿伟，高波，等. 天然气来源的多种途径及其意义. 石油与天然气地质, 2006, 26: 393-401

3 Berner U, Falter E. Empirical carbon isotope maturity relationships for gases from algal kerogens and terrigenous organic matter, based on dry, open system pyrolysis. Org Geochem, 1996, 24: 947-955

4 Cramer B, Faber E, Gerling P, et a1. Reaction kinetics of stable carbon isotopes in natural gas-insights from dry, open system pyrolysis experiments. Energy Fuel, 2001, 15: 517-532

5 Behar F, Kressmann S, Rudkiewicz L, et a1. Experimental simulation in a confined system and kinetic modeling of kerogen and oil cracking. Org Geochem, 1992, 19: 173-189

6 Cramer B. Methane generation from coal during open system pyrolysis investigated by isotope specific, Gaussian distributed reaction kinetics. Org Geochem, 2004, 35: 379-392

7 王振平，付晓泰，卢双舫，等. 原油裂解成气模拟实验、产物特征及其意义. 天然气工业, 2001, 21: 12-15

8 王铜山, 耿安松, 熊永强, 等. 塔里木盆地海相原油及其沥青质裂解生气动力学模拟研究. 石油学报, 2008, 29: 167-174

9 田辉, 肖贤明, 李贤庆, 等. 海相干酪根与原油裂解气甲烷生成及碳同位素分馏的差异研究. 地球化学, 2007, 36: 71-77

10 米敬奎，戴金星，张水昌，等. 煤在 2 种不同体系的生气能力研究. 天然气地球科学, 2007, 18: 245-249

11 肖芝华, 胡国艺, 李志生. 封闭体系下压力变化对烃源岩产气率的影响. 天然气地球科学, 2007, 18: 284-288

12 郑伦举, 秦建中, 何生, 等. 地层孔隙热压生排烃模拟实验初步研究. 石油实验地质, 2009, 31: 296-304

13 Prinzhofer A, Huc A Y. Genetic and post-genetic molecular and isotopic fractionations in natural gases. Chem Geol, 1995, 126: 281-290

14 刘文汇. 海相层系多种烃源及其示踪体系研究进展. 天然气地球科学, 2009, 20: 1-7

15 戴金星. 威远气田成藏期及气源. 石油实验地质, 2003, 25: 473-479

16 蔡勋育, 朱扬明, 黄仁春. 普光气田沥青地球化学特征及成因. 石油与天然气地质, 2006, 27: 340-348

17 秦建中, 付小东, 刘效曾. 四川盆地东北部气田海相碳酸盐岩储层固体沥青研究. 地质学报, 2007, 81: 1065-1071

18 郑伦举, 秦建中, 张渠, 等. 中国海相不同类型原油与沥青生气潜力研究. 地质学报, 2008, 821: 360-365

19 雷天柱, 夏燕青, 郑建京, 等. 酮一一有机酸盐生烃过程中的重要产物. 矿物岩石, 2009, 29: 84-87

20 熊永强, 张海祖, 耿新华, 等. 正十八烷的裂解及其地球化学意义. 科学通报, 2004, 49(增刊): 72-75

21 徐永昌. 天然气成因理论及应用. 北京: 科学出版社, 1994. 97-106

22 王杰，陈践发，王铁冠，等. 松辽盆地双城一太平川地区天然气成因类型及气源. 石油学报, 2006, 27: 16-21

23 赵孟军, 曾凡刚, 秦胜飞, 等. 塔里木发现和证实两种裂解气. 天然气工业, 2001, 21: 35-39

24 王红军, 周兴熙. 塔里木盆地典型海相成因天然气气藏成藏模式. 石油学报, 2001, 22: 14-18

25 Behar F, Vandenbroucke M, Teermann S C, et al. Experimental simulation of gas generation from coals and a marine kerogen. Chem Geol, 1995, 126: 247-260 